\title{
KARAKTERISTIK MEKANIS CAMPURAN LASTON ATAS DENGAN BUBUK GRAFIT SEBAGAI BAHAN PENGGANTI FILLER
}

\author{
Lidwina Sri Ayu DR Sianturi ${ }^{1}$ dan Anissa Noor Tajudin ${ }^{2}$ \\ ${ }^{1}$ Program Studi Sarjana Teknik Sipil, Universitas Tarumanagara, Jl. Letjen S. Parman No.1 Jakarta \\ lidwina.325160175@stu.untar.ac.id \\ ${ }^{2}$ Program Studi Sarjana Teknik Sipil, Universitas Tarumanagara, Jl. Letjen S. Parman No.1 Jakarta \\ anissat@ft.untar.ac.id
}

\begin{abstract}
In road pavement modifications, many use materials that have good conductivity to be added to the mixture. One of the conductive materials that can be used for pavement is graphite powder. Graphite is usually found in pencils, raw materials for batteries, etc. The use of graphite powder in the pavement mixture has many benefits such as selfhealing, self-monitoring, etc. This research uses graphite powder as filler replacement material. Tests conducted in this study is testing the characteristics of the mixture in accordance with the provisions in force in Indonesia. This study uses graphite powder with variations of 5\%,10\%, 15\%, and $20 \%$ with asphalt content of 5.7\%. From the results of testing the characteristics of the mixture continued with the determination of optimum graphite powder content using the narrow range method. Then proceed with the mechanistic response analysis using the KENPAVE program. The results of this study largely meet the requirements of the General Specifications of the Directorate General of Highways 2018 Edition Division 6 and the 2017 Pavement Road Design Manual. The results of this study indicate that the use of graphite powder as a filler substitute can be used in Indonesia.
\end{abstract}

Keywords: graphite; filler; mechanic; Marshall; KENPAVE

\begin{abstract}
ABSTRAK
Pada perkerasan jalan modifikasi, banyak menggunakan bahan yang mempunyai konduktivitas yang baik untuk ditambahkan dalam campuran. Salah satu bahan konduktif yang dapat digunakan untuk campuran perkerasan adalah bubuk grafit. Grafit biasanya terdapat pada pensil, bahan baku baterai kering, dll. Penggunaan bubuk grafit dalam perkerasan memiliki banyak manfaat seperti self-healing, self- monitoring, dll. Penelitian ini menggunakan bubuk grafit sebagai bahan pengganti filler. Pengujian yang dilakukan pada penelitian ini adalah pengujian karakteristik campuran yang sesuai dengan ketentuan yang berlaku di Indonesia. Penelitian ini menggunakan bubuk grafit dengan variasi 5\%,10\%, 15\%, dan 20\% dengan kadar aspal 5,7\%. Dari hasil pengujian karakteristik campuran dilanjutkan dengan penentuan kadar bubuk grafit optimum dengan metode narrow range. Kemudian dilanjutkan dengan analisis respons mekanistik dengan menggunakan program KENPAVE. Hasil penelitian ini sebagian besar memenuhi persyaratan Spesifikasi Umum Direktorat Jendral Bina Marga Edisi 2018 Divisi 6 dan Manual Desain Perkerasan Jalan 2017. Hasil penelitian ini menunjukkan bahwa penggunaan bubuk grafit sebagai bahan pengganti filler dapat digunakan di Indonesia.
\end{abstract}

Kata kunci: grafit; filler; mekanis; Marshall; KENPAVE

\section{PENDAHULUAN}

Jalan raya merupakan prasarana transportasi yang sangat diperlukan dalam berbagai aspek kehidupan. Penggunaan jalan raya yang terus menerus dapat menyebabkan kerusakan pada perkerasan jika tidak diakukan pemeliharaan. Kerusakan pada jalan merupakan salah satu yang menghambat pergerakan lalu lintas. Dikarenakan pergerakan lalu lintas yang terhambat, maka aktivitas manusia dapat teganggu. Kerusakan jalan juga dapat mengganggu aktivitas ekonomi seperti pengiriman barang, dll. Karena jalan merupakan hal yang sangat penting dalam kehidupan seharihari, diperlukan kualitas yang baik untuk keamanan dan kenyamanan pengguna jalan. Untuk dapat membuat jalan yang berkualitas, diperlukan penelitian dan perencanaan perkerasan yang baik.

Saat ini banyak sekali penelitian yang memodifikasi perkerasan jalan dengan berbagai bahan konduktif. Salah satunya adalah bubuk grafit. Salah satu penelitian terdahulu mengenai pemanfaatan bubuk grafit sebagai bahan pengganti filler adalah sebagai pemantauan diri dari kerusakan. Dari hasil penelitian Liu dkk (2007), menunjukkan bahwa peningkatan 
konduktansi listrik dapat membuat campuran aspal dasar yang bersifat isolator menjadi konduktor, yang membuat pemantauan sendiri aspal perkerasan menjadi layak melalui piezoresistive campuran aspal konduktif listrik.

Karena grafit memiliki banyak manfaat saat dicampurkan dalam perkerasan jalan, maka perlu dilakukan penelitian lebih lanjut mengenai karakteristik campuran perkerasan yang menambahkan grafit dan pemanfaatannya di Indonesia. Walaupun banyak penelitian tentang penggunaan grafit dilakukan di negara subtropis, beberapa pemanfaatan bubuk grafit lainnya bisa diterapkan di Indonesia dengan tujuan meningkatkan kualitas dan kinerja perkerasan itu sendiri dan diharapkan dapat menyelesaikan permasalahan yang berhubungan dengan perkerasan jalan. Untuk dapat diterapkan di Indonesia, campuran yang mengandung bahan grafit perlu dilakukan pengujian yang sesuai dengan standar yang berlaku di Indonesia. Dalam penelitian ini akan dilakukan berbagai pengujian karakteristik campuran yang sesuai dengan ketentuan yang berlaku di Indonesia seperti Spesifikasi Umum Direktorat Jendral Bina Marga.

\section{Filler}

Spesifikasi Umum Direktorat Jendral Bina Marga Edisi 2018 Divisi 6 menyebutkan bahwa bahan pengisi yang ditambahakan (filler added) terdiri atas debu batu kapur atau debu kapur padam yang sesuai dengan AASHTO M30389 (2006), semen atau mineral yang berasal dari Asbuton yang sumbernya disetujui oleh Direksi Pekerjaan. Bahan pengisi yang ditambahkan harus kering dan bebas dari gumpalan-gumpalan bila diuji dengan pengayakan. Harus mengandung bahan yang lolos ayakan No. 200 (75 mikron) tidak kurang dari 75\% terhadap beratnya kecuali untuk mineral Asbuton. Mineral Asbuton harus mengandung bahan yang lolos ayakan No. 100 (150 mikron) tidak kurang dari $95 \%$ terhadap beratnya.

\section{Bubuk grafit sebagai bahan pengganti filler}

Dari hasil penelitian Wu, dkk (2006), menunjukkan bahwa komposit berbasis aspal konduktif secara elektrik memiliki pemantauan diri yang baik dengan merasakan kerusakan sendiri, deformasi, dan kegagalan lainnya. Dengan kandungan grafit yang meningkat sampai batas tertentu, partikel grafit tunggal berkumpul dan membentuk akses konduktif elektrik yang berkelanjutan, dan hambatan kontak antara partikel grafit mengatur resistivitas. Jika struktur interior sampel diubah dari pembebanan eksterior, yang akan mengubah antarmuka kontak partikel grafit, maka akibatnya akan mempengaruhi jaringan konduktif listrik. Jadi itu memiliki arti penting untuk membangun korelasi antara resistensi dan struktur.

Dari hasil penelitian Kok, dkk (2017), menunjukkan uji mekanis seperti stabilitas dan aliran Marshall, modulus kekakuan tarik tidak langsung dan uji kelelahan tarik tidak langsung diterapkan pada campuran perkerasan pada tiga proporsi berat grafit yang berbeda, yaitu 10\%, 15\%, dan 20\% dari bitumen. Kandungan grafit 15\% adalah rasio efektif ketika mempertimbangkan respons elastis, energi yang diserap, perilaku deformasi setelah retak awal dan jumlah pengisian penuh yang diinduksi ke deteriorasi. Grafit umumnya digunakan untuk meningkatkan sifat termal dalam campuran juga ditentukan untuk berkontribusi pada sifat mekanik campuran pada suhu sedang.

\section{Karakteristik Marshall}

Menurut Hardiyatmo (2015), Kinerja campuran aspal panas sangat bergantung pada karakteristik Marshall, yang terdiri dari parameter-parameter: stabilitas, kepadatan, rongga di dalam agregat mineral (voids in the mineral aggregate, VMA), rongga di dalam campuran (voids in the mix, VITM), rongga terisi dengan aspal (voids filled with asphalt, VFWA), keluluhan (flow) dan Marshall Quotient (MQ).

Rongga udara di dalam campuran (voids in the mix, VITM atau VIM) aspal dipadatkan adalah rasio antara volume udara terhadap volume bulk campuran dipadatkan, yang dinyatakan oleh:

$$
V I T M=\frac{G_{m m}-G_{m b}}{G_{m m}} \times 100
$$

dengan $\mathrm{Gmm}=$ berat jenis maksimum campuran aspal tidak dipadatkan, Gmb = berat jenis bulk campuran dipadatkan.

Persen rongga di dalam agregat mineral (voids in the mineral aggregate, VMA) dalam campuran yang dipadatkan, didefinisikan sebagai ruang rongga intergranuler di antara partikel agregat dalam campuran aspal yang dipadatkan, termasuk rongga udara dan kandungan aspal efektif, dinyatakan sebagai persen dari volume total, yang dinyatakan oleh:

$$
\mathrm{VMA}=100-\frac{G_{m b} P_{s}}{G_{s b}}
$$

dengan $\mathrm{Gmb}=$ berat jenis bulk campuran, Ps = kadar agergat (persen terhadap berat total campuran), Gsb = berat jenis bulk total dari agregat.

Persen rongga terisi dengan aspal (voids filled with asphalt, VFWA atau VFA) dalam campuran aspal dipadatkan adalah rasio antara volume aspal efektif terhadap volume rongga dalam agregat mineral, yang dinyatakan oleh: 


$$
V F W A=\frac{V M A-V I M}{V M A} \times 100
$$

dengan VMA = persen rongga udara di dalam agregat; VIM = persen rongga udara di dalam campuran aspal dipadatkan.

\section{Mekanistik empiris}

Menurut Heliyati dan Kushari (2016) metode desain mekanistik-empiris didasarkan pada mekanika bahan. Input pada metode ini adalah beban lalu lintas, luas kotak area ban, jarak antar ban, jarak antar sumbu, tekanan ban, poisson's ratio, modulus elastis dan ketebalan lapisan. Untuk output dalam metode perkerasan ini adalah regangan dan tegangan yang digunakan untuk menganalisis kerusakan (fatigue cracking, rutting, permanent deformation) untuk mendapatkan tebal perkerasan efektif.

\section{METODE PENELITIAN}

Pada penelitian ini dilakukan di laboratorium Perkerasan Jalan Raya Universitas Tarumanagara Kampus 1, dengan menggunakan tipe AC-WC (Asphalt Concrete - Wearing Course) dengan panduan Bina Marga dan pencampuran bubuk grafit menggunakan metode Dry-Mix.

\section{Tahap persiapan}

Merupakan tahapan mempersiapkan agregat kasar, agregat halus, filler, dan aspal AC 60/70 yang akan digunakan. Untuk mempersiapkan bahan yang digunakan dilakukan pemeriksaan agar sesuai dengan Spesifikasi Umum Direktorat Jendral Bina Marga Edisi 2018 Divisi 6. Pemeriksaan agregat dan filler berupa analisa saringan, pemeriksaan keaudan mengguanakan mesin Los Angeles untuk agregat kasar, pemeriksaan berat jenis, dan kelekatan agregat terhadap aspal. Pemeriksaan aspal berupa pemeriksaan penetrasi aspal, pemeriksaan titik nyala dan titik bakar aspal, pemeriksaan titik lembek aspal, pemeriksaan daktilitas aspal, dan pemeriksaan berat jenis aspal.

\section{Perancangan benda uji}

Perancangan benda uji pada penelitian ini dapat dilihat pada Tabel 1.

Tabel 1. Rancangan gradasi agregat untuk campuran dengan bubuk grafit sebagai pengganti filler

\begin{tabular}{|c|c|c|c|c|c|c|c|c|c|c|}
\hline \multirow{3}{*}{ Bahan } & \multirow{2}{*}{\multicolumn{2}{|c|}{ Saringan }} & \multicolumn{8}{|c|}{ Variasi Bubuk Grafit } \\
\hline & & & \multicolumn{2}{|c|}{$5 \%$} & \multicolumn{2}{|c|}{$10 \%$} & \multicolumn{2}{|c|}{$15 \%$} & \multicolumn{2}{|c|}{$20 \%$} \\
\hline & $\mathrm{mm}$ & $\#$ & (gram) & $\begin{array}{c}\text { Lolos } \\
(\%)\end{array}$ & (gram) & $\begin{array}{l}\text { Lolos } \\
(\%)\end{array}$ & (gram) & $\begin{array}{l}\text { Lolos } \\
(\%)\end{array}$ & (gram) & $\begin{array}{c}\text { Lolos } \\
(\%)\end{array}$ \\
\hline \multirow{4}{*}{$\begin{array}{c}\text { Agregat Kasar } \\
\quad(42,25 \%)\end{array}$} & 19,1 & $3 / 4^{\prime \prime}$ & 0 & 0 & 0 & 0 & 0 & 0 & 0 & 0 \\
\hline & 12,7 & $1 / 2^{\prime \prime}$ & 42 & 3,5 & 42 & 3,5 & 42 & 3,5 & 42 & 3,5 \\
\hline & 9,52 & $3 / 8^{\prime \prime}$ & 153 & 12,7 & 153 & 12,7 & 153 & 12,7 & 153 & 12,7 \\
\hline & 4,76 & $\# 4$ & 312 & 26 & 312 & 26 & 312 & 26 & 312 & 26 \\
\hline \multirow{6}{*}{$\begin{array}{l}\text { Agregat Halus } \\
\quad(51,67 \%)\end{array}$} & 2,36 & $\# 8$ & 227 & 18,9 & 227 & 18,9 & 227 & 18,9 & 227 & 18,9 \\
\hline & 1,18 & $\# 16$ & 156 & 13 & 156 & 13 & 156 & 13 & 156 & 13 \\
\hline & 0,59 & $\# 30$ & 72 & 6 & 72 & 6 & 72 & 6 & 72 & 6 \\
\hline & 0,279 & $\# 50$ & 64 & 5,3 & 64 & 5,3 & 64 & 5,3 & 64 & 5,3 \\
\hline & 0,149 & $\# 100$ & 56 & 4,7 & 56 & 4,7 & 56 & 4,7 & 56 & 4,7 \\
\hline & 0,074 & $\# 200$ & 45 & 3,8 & 45 & 3,8 & 45 & 3,8 & 45 & 3,8 \\
\hline \multirow[b]{2}{*}{ Filler $(6,08 \%)$} & PAN & & 69,35 & 5,8 & 65,7 & 5,5 & 62,05 & 5,2 & 58,4 & 4,9 \\
\hline & $\begin{array}{c}\text { Bubuk } \\
\text { Grafit } \\
\end{array}$ & & 3,65 & 0,3 & 7,3 & 0,6 & 10,95 & 0,9 & 14,6 & 1,2 \\
\hline \multicolumn{3}{|c|}{ Jumlah } & 1200 & 100 & 1200 & 100 & 1200 & 100 & 1200 & 100 \\
\hline
\end{tabular}

\section{Pembuatan benda uji}

Berikut adalah cara pembuatan benda uji untuk pengujian Marshall:

- Agregat kasar, halus filler dan bubuk grafit dikumpulkan, agregat kasar yang dipakai dibersihkan dari lumpur dan kotoran yang menempel, kemudian menghilangkan kadar airnya dengan oven selama 24 jam.

- Agregat yang telah kering ditimbang sesuai perencanaan komposisi gradasi benda uji dengan berat kontrol adalah 1200 gram. Jika ada variasi penambahan bubuk grafit, masukkan filler dan bubuk grafit sesuai dengan rancangan jumlahnya. 
- Campuran agregat yang telah ditimbang kemudian diaduk agar merata dan dipanaskan sampai suhu pencampuran, bertujuan agar agregat didapatkan bersuhu sama dengan aspal, dikarenakan agregat adalah butiran yang memiliki pori sehingga cepat menyerap panas. Maka agregat yang telah dipanaskan cepat turun suhunya.

- Aspal yang akan dicampur dengan agregat dan bubuk grafit harus dipanaskan sesuai dengan suhu pencampuran.

- Berat aspal pada saat pencampuran antara aspal dengan pencampuran agregat dan bubuk grafit disesuaikan dengan benda uji, kemudian diaduk dengan mempertahankan suhu pencampuran sampai aspal menutupi seluruh permukaan agregat.

- Kemudian campuran dimasukkan ke dalam cetakan. Cetakan yang digunakan dalam keadaan bersih dan diberi oli agar benda uji tidak rusak pada saat dikeluarkan dari cetakan. Pada bagian atas dan bawah diberikan selembar kertas.

- Setelah campuran dimasukkan ke dalam cetakan, dirojok atau ditusuk sebanyak 15 kali pada sisi pinggir dan 10 kali pada bagian tengah agar benda uji tidak berongga.

- Kemudian benda uji ditumbuk menggunakan alat penumbuk sebanyak 75 kali di sisi atas dan bawah benda uji untuk memadatkan benda uji.

- Setelah pemadatan benda uji, benda uji didiamkan sebentar hingga suhu ruangan kemudian dikeluarkan dari cetakan menggunakan ejector.

\section{Pengujian Marshall}

Berikut ini adalah tata cara pengujian Marshall:

- Benda uji yang telah dikeluarkan dari cetakan dibersihkan pada kedua sisi dari kotoran-kotoran yang menepel.

- Setiap benda uji diukur tinggiannya pada tiga tempat berbeda kemudian dirata-rata.

- Benda uji ditimbang dalam keadaan kering untuk mengetahui berat keringnya.

- Benda uji direndam selama minimal 10 menit pada suhu ruangan agar tercipta benda uji yang jenuh air.

- Setelah direndam benda uji kemudian ditimbang dalam air sehingga diketahui berat benda uji dalam air.

- Kemudian benda uji diangat dari bak perendaman dan dikeringkan permukaannya sehingga tercipta berat kering permukaan atau SSD. Benda uji kemudian ditimbang.

- Setelah itu benda uji direndam dalam water bath selama 30 menit untuk perendaman standar.

- Bagian dalam permukaan kepala penekan dibersihkan dan diberi plastik agar benda uji mudah dilepaskan setelah pengujian.

- Benda uji dikeluarkan dari water bath setelah direndam 30 menit, lalu diletakkan tepat ditengah cincin penguji. Kemudian arloji kelelehan (flowmeter) dipasang pada dudukan diatas cincin penguji.

- Kepala penekan dinaikkan hingga menyentuh atas cincin penguji, kemudian diatur kedudukan jarum arloji penekan dan arloji kelelehan pada angka nol.

- Pembebanan dilakukan dengan kecepatan tetap $51 \mathrm{~mm}$ (2 inch) per menit, hingga kegagalan benda uji terjadi, yaitu pada saat arloji pembebanan berhenti dan mulai kembali berputar menurun, pada saat itu dibaca arloji kelelehan. Titik pembacaan pada saat benda uji mengalami kegagalan adalah merupakan nilai stabilitas Marshall.

- Setelah pengujian selesai, kepala penekan diambil, bagian atas dibuka, dan benda uji dikeluarkan. Benda uji berikutnya siap diuji seperti langkah sebelumnya.

\section{Evaluasi perkerasan menggunakan program KENPAVE}

Tahapan perhitungan evaluasi perkerasan pada bagan desain Manual Perkerasan Jalan 2017 dengan menggunakan program KENPAVE adalah sebagai berikut:

- Menentukan data struktur perkerasan yaitu modulus elastisitas, poisson ratio, dan tebal perkerasan berdasarkan perencanaan Manual Perkerasan Jalan 2017. Modulus elastisitas didapat dari nilai stabilitas yang dikonfersikan ke modulus elastisitas pada penelitian ini, sedangkan data lainnya mengikuti percobaan sebelumnya.

- Menghitung parameter dengan menggunakan teori sistem lapis banyak program KENPAVE sehingga diperoleh hasil regangan yang terjadi pada struktur perkerasan.

- Nilai regangan tekan di bawah lapis pondasi bawah atau permukaan tanah dasar dapat digunakan untuk mengetahui repetisi izin deformasi permanen $(\mathrm{Nd})$.

- Memeriksa nilai Nd dengan repetisi beban rencana (Nrencana)

- Jika Nd lebih besar dari Nrencana maka tebal perkerasan yang dihasilkan melalui perencanaan Manual Perkerasan Jalan 2017 mampu menahan beban lalu lintas sesuai dengan yang direncanakan. 
- Jika Nd lebih kecil dari Nrencana, maka tebal perkerasan yang dihasilkan melalui Manual Perkerasan Jalan 2017 tidak mampu menahan beban lalu lintas yang direncanakan berdasarkan teori sistem lapis banyak program KENPAVE.

\section{HASIL DAN PEMBAHASAN}

\section{Hasil pengujian Marshall}

Tabel hasil uji Marshall dengan penggunaan bubuk grafit sebagai bahan pengganti filler dapat dilihat pada Tabel 2.

Tabel 2. Hasil pengujian Marshall dengan penambahan bubuk grafit

\begin{tabular}{cccccc}
\hline \multirow{2}{*}{ Kriteria } & \multirow{2}{*}{ Spesifikasi } & \multicolumn{4}{c}{ Kadar Bubuk Grafit } \\
\cline { 3 - 6 } & $>15 \%$ & $16,22 \%$ & $15,71 \%$ & $15,53 \%$ & $15,25 \%$ \\
\hline VMA & $3-5 \%$ & $3,55 \%$ & $3,00 \%$ & $2,76 \%$ & $2,44 \%$ \\
\hline VITM & $>65 \%$ & $78,10 \%$ & $81,16 \%$ & $82,25 \%$ & $84,02 \%$ \\
\hline VFWA & $>800 \mathrm{~kg}$ & $1224 \mathrm{~kg}$ & $1372 \mathrm{~kg}$ & $1428 \mathrm{~kg}$ & $1387 \mathrm{~kg}$ \\
\hline Stabilitas & $>3 \mathrm{~mm}$ & $3,7 \mathrm{~mm}$ & $3,7 \mathrm{~mm}$ & $3,33 \mathrm{~mm}$ & $3,03 \mathrm{~mm}$ \\
\hline Flow & $>250 \mathrm{~kg} / \mathrm{mm}$ & $334 \mathrm{~kg} / \mathrm{mm}$ & $364 \mathrm{~kg} / \mathrm{mm}$ & $428 \mathrm{~kg} / \mathrm{mm}$ & $457 \mathrm{~kg} / \mathrm{mm}$ \\
\hline MQ & & & & &
\end{tabular}

Dapat dilihat bahwa penggunaan bubuk grafit membuat nilai VMA dari penelitian ini menurun. Nilai VMA pada percobaan ini turun dikarenakan penambahan grafit menyebabkan jarak antar agregat semakin rapat karena bentuk butir dari grafit itu hexagonal sehingga pada proses perekatan, grafit lebih mudah merekat dengan agregat ketika ditambahkan aspal, sehingga jarak antar agregat berkurang (Liu dan $\mathrm{Wu}, 2010$ ).

Dalam penelitian ini didapatkan nilai VITM yang kecil. Hal ini dikarenakan gradasi agregat yang rapat dan kadar aspal yang tinggi sehingga rongga udara kecil. Penambahan kadar bubuk grafit dalam campuran akan menurunkan nilai VITM. Hal ini dikarenakan bubuk grafit yang digunakan sebagai pengganti filler memiliki berat jenis lebih rendah dari agregat, sehingga dengan berat yang sama volume rongga yang akan diisi oleh filler menjadi semakin besar dan rongga udara berkurang.

Dalam penelitian ini nilai VFWA meningkat seiring dengan penambahan kadar bubuk grafit dalam percobaan. Hal ini disebabkan bubuk grafit yang digunakan sebagai pengganti filler memiliki berat jenis lebih rendah dari agregat, sehingga dengan berat yang sama volume rongga yang akan diisi oleh filler menjadi semakin besar dan rongga udara berkurang. Jumlah rongga yang terisi aspal berkebalikan dengan rongga udara, sehingga ketika rongga udara mengalami penurunan, rongga yang dapat terisi aspal akan bertambah.

Dalam penelitian ini, nilai stabilitas meningkat dari penggunaan bubuk grafit sebanyak 5\% hingga $15 \%$ dan penurunan pada penambahan $20 \%$. Hal ini menunjukkan bahwa penambahan grafit $5 \%$ hingga $15 \%$ dalam campuran merupakan penambahan grafit yang menuju keadaan optimum penambahan grafit. Dalam penambahan grafit $20 \%$ dalam campuran, kadar grafit sudah melewati kadar penambahan grafit optimum sehingga nilainya turun dari sebelumnya.

Pada penelitian ini nilai flow cenderung turun seiring dengan penambahan penggunaan grafit dalam campuran. Maka dapat disimpulkan pada penambahan penggunaan bubuk grafit dalam penelitian ini menyebabkan campuran semakin kaku karena mengalami penurunan nilai.

Dapat dilihat bahwa nilai MQ pada penelitian ini meningkat. Semakin meningkat nilai MQ berarti menunjukkan bahwa setiap penambahan bubuk grafit membuat campuran menjadi semakin kaku.

\section{Kadar bubuk grafit optimum dalam campuran}

Pada penelitian ini, penggunaan bubuk grafit dalam campuran beragam yaitu dengan kadar 5\%, 10\%, $15 \%$, dan $20 \%$. Dari hasil pengujian Marshall dalam penelitian ini didapatkan beberapa parameter yang menunjukkan bahwa campuran dengan penggunaan bubuk grafit dengan kadar beragam layak dan sesuai dengan Spesifikasi Umum Direktorat Jendral Bina Marga Edisi 2018 Divisi 6. Parameter yang ditinjau dalam penelitian ini adalah VMA, VITM, VFWA, stabilitas, flow, dan MQ. Dari parameter tersebut dapat digunakan untuyk menentukan kadar penggunaan bubuk grafit optimum pada penelitian ini dengan metode narrow range. Metode narrow range merupakan metode yang menggunakan nilai tengah dari batasan-batasan nilai maksimum dan minimum dari parameter yang didapat dalam penelitian ini. Hasil dari metode narrow range pada penelitian ini akan ditampilkan pada Gambar 1. 


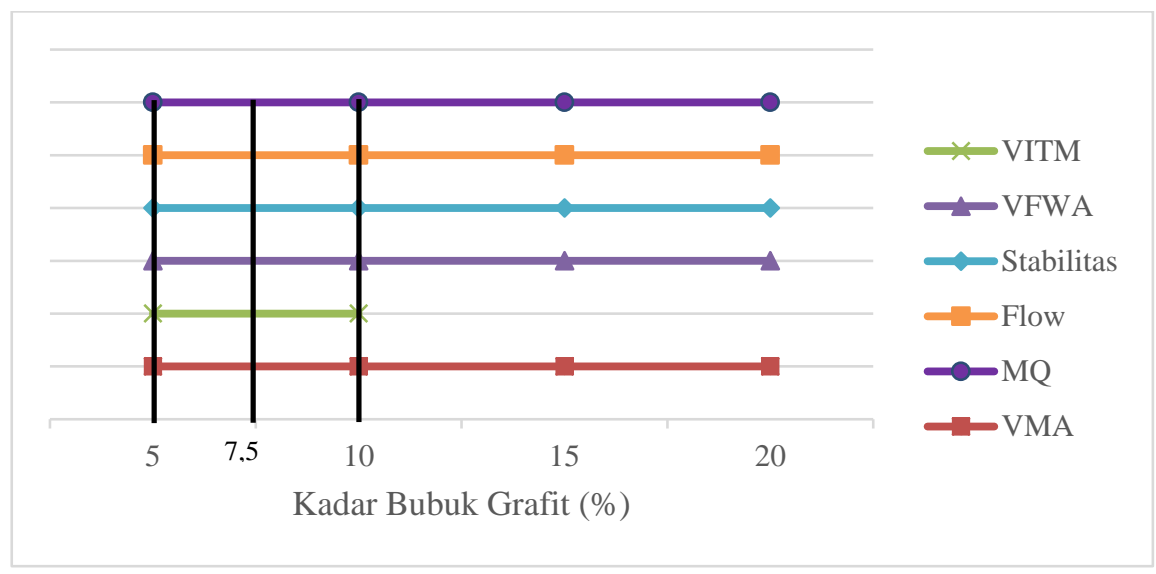

Gambar 1. Narrow range kadar bubuk grafit optimum

Dari Gambar 1 didapatkan nilai kadar optimum penambahan bubuk grafit dalam penelitian ini adalah sebesar 7,5\% dengan parameter yang memenuhi Spesifikasi Umum Direktorat Jendral Bina Marga Edisi 2018 Divisi 6 adalah kadar minimum $5 \%$ dan kadar maksimum $10 \%$.

\section{Analisis respons mekanistik}

Respons mekanistik pada penelitian ini adalah regangan vertikal dan horizontal. Input data dalam program KENPAVE berupa modulus elastisitas, poisson ratio, dan tebal di setiap lapisan. Untuk nilai poisson ratio pada perkerasan AC WC adalah 0,4; untuk lapisan AC BC adalah 0,4; untuk AC Base adalah 0,4 ; untuk LPA kelas A adalah 0,35; untuk tanah perbaikan adalah 0,35 ; untuk tanah dasar adalah 0,35 , sedangkan untuk poisson ratio lapisan HRS-WC adalah 0,4 ; untuk HRS base adalah 0,4 ; untuk LPA kelas A adalah 0,35; untuk LPA kelas A kerikil alam adalah 0,35 ; untuk tanah perbaikan adalah 0,35 ; untuk tanah dasar adalah 0,35 dan beban yang akan dimasukkan ke dalam program KENPAVE untuk beban $100 \%$ adalah $540 \mathrm{Kpa}$. Hasil pengujian analisis respons mekanistik dapat dilihat pada Tabel 3 berikut.

Tabel 3. Hasil pengujian analisis respons mekanistik

\begin{tabular}{cccc}
\hline $\begin{array}{c}\text { Kadar } \\
\text { Bubuk } \\
\text { Grafit }\end{array}$ & $\begin{array}{c}\text { Regangan } \\
\text { Horizontal }\end{array}$ & $\begin{array}{c}\text { Regangan } \\
\text { Vertikal }\end{array}$ & $\begin{array}{c}\text { Repetisi Izin } \\
\text { Deformasi } \\
\text { Permanen }\end{array}$ \\
\hline $5 \%$ & $2,484 \mathrm{E}-04$ & $3,998 \mathrm{E}-04$ & 3.685 .370 .129 \\
\hline $10 \%$ & $2,477 \mathrm{E}-04$ & $3,964 \mathrm{E}-04$ & 3.912 .416 .837 \\
\hline $15 \%$ & $2,474 \mathrm{E}-04$ & $3,953 \mathrm{E}-04$ & 3.989 .265 .485 \\
\hline $20 \%$ & $2,476 \mathrm{E}-04$ & $3,961 \mathrm{E}-04$ & 3.933 .206 .453 \\
\hline
\end{tabular}

Dalam penelitian ini, nilai regangan horizontal dan vertikal berbanding terbalik dengan nilai stabilitas. Nilai regangan horizontal dan vertikal menurun dari penambahan bubuk grafit sebanyak 5\% hingga 15\% dan meningkat pada penambahan $20 \%$. Hal ini menunjukkan bahwa penambahan grafit $5 \%$ hingga $15 \%$ dalam campuran merupakan penambahan grafit yang menuju keadaan optimum penambahan grafit. Dalam penambahan grafit $20 \%$ dalam campuran, kadar grafit sudah melewati kadar penambahan grafit optimum sehingga nilainya naik dari sebelumnya.

Nilai Nd (Repetisi Izin Deformasi Permanen) menunjukan batas repetisi beban kerusakan rutting. Pada perkerasan FFF1 untuk variasi penggunaan bubuk grafit yang berbeda - beda yaitu dengan penambahan 5\%, 10\%, 15\%, dan 20\% bubuk grafit tidak mengalami kerusakan rutting karena nilai Nd yang di hasilkan tidak kurang dari repetisi rencana (Nr) perkerasan FFF1 sesuai dengan Manual Desain Perkerasan Jalan 2017 yaitu sebesar 2.000.000. 


\section{KESIMPULAN DAN SARAN}

\section{Kesimpulan}

Berdasarkan hasil penelitian yang telah dilakukan menggunakan benda uji campuran Asphalt Concrete-Wearing Course (AC-WC) dengan menggunakan bubuk grafit sebagai pengganti filler, dapar disimpulkan bahwa:

1. Penggunaan bubuk grafit sebagai pengganti filler pada penelitian membuat nilai VITM turun seiring dengan pertambahan presentase bubuk grafit dalam campuran. Hal ini dikarenakan gradasi agregat yang rapat dan kadar aspal yang tinggi.

2. Penggunaan bubuk grafit sebagai pengganti filler pada penelitian ini membuat nilai VMA turun seiring dengan pertambahan presentase bubuk grafit dalam campuran. Hal ini dikarenakan penambahan grafit menyebabkan jarak antar agregat semakin rapat karena bentuk butir dari grafit itu hexagonal sehingga pada proses perekatan, grafit lebih mudah merekat dengan agregat ketika ditambahkan aspal.

3. Penggunaan bubuk grafit sebagai pengganti filler pada penelitian ini meningkatkan nilai VFWA seiring dengan pertambahan presentase bubuk grafit dalam campuran. Hal ini dikarenakan bubuk grafit yang digunakan sebagai pengganti filler memiliki berat jenis lebih rendah dari agregat sehingga dengan berat yang sama, volume rongga yang akan diisi oleh filler menjadi semakin besar dan rongga udara berkurang.

4. Nilai stabilitas pada percobaan ini meningkat pada penggunaan bubuk grafit $5 \%$ hingga $15 \%$ dan mengalami penurunan pada penggunaan bubuk grafit 20\%. Hal ini menunjukkan bahwa penggunaan bubuk grafit $5 \%$ hingga $15 \%$ dalam campuran merupakan penambahan grafit yang menuju keadaan optimum. Dalam penggunaan bubuk grafit $20 \%$ dalam campuran, kadar grafit sudah melewati kadar penambahan grafit optimum sehingga nilainya turun dari sebelumnya.

5. Nilai flow pada penelitian ini cenderung turun seiring dengan penambahan penggunaan bubuk grafit.

6. Nilai MQ pada penelitian meningkat seiring dengan penambahan penggunaan bubuk grafit. Hal ini menunjukkan bahwa semakin banyak bubuk grafit yang digunakan dalam campuran pekerasan, maka perkerasan akan semakin kaku.

7. Pada perkerasan FFF1 untuk variasi penggunaan bubuk grafit yang berbeda - beda yaitu dengan penambahan $5 \%, 10 \%, 15 \%$, dan $20 \%$ bubuk grafit tidak mengalami kerusakan rutting karena nilai Nd yang di hasilkan tidak kurang dari repetisi rencana $(\mathrm{Nr})$.

8. Kadar bubuk grafit optimum yang didapatkan dari penelitian ini adalah 7,5\% yang didapatkan dari metode Narrow Range.

\section{Saran}

Berdasarkan hasil penelitian yang telah dilakukan menggunakan benda uji campuran Asphalt Concrete-Wearing Course (AC-WC) dengan menggunakan bubuk grafit sebagai pengganti filler memiliki beberapa kekurangan. Berikut beberapa saran untuk penelitian selanjutnya, yaitu:

1. Perlunya penelitian lebih lanjut mengenai nilai stabilitas yang dikonversikan menjadi modulus elastisitas.

2. Perlunya penelitian lebih lanjut untuk menentukan nilai kadar optimum penggunaan bubuk grafit dengan variasi yang lebih banyak.

\section{DAFTAR PUSTAKA}

Hardiyatmo, Hary Christady. "Pemeliharaan Jalan Raya". Yogyakarta: Gadjah Mada University Press, 2015. 119-122. Cetak.

Heliyati, Carolina Aprilia and Berlian Kushari. "Perbandingan Perencanaan Tebal Perkerasan Lentur Jalan dengan Metode Empirik dan Mekanistik-Empirik Pada Ruas Jalan Mlati-Cebongan-Seyegan". The 19th International Symposium of FSTPT, Islamic University of Indonesia. (2016): 981-991. Prosiding Forum Studi Transportasi antar Perguruan Tinggi. Web. 13 Juni. 2020.

Indonesia. Surat Edaran Direktorat Jendral Bina Marga Nomor: 04/SE/Db/2017: Manual Desain Perkerasan Jalan 2017. Jakarta: Direktorat Jendral Bina Marga, 2017.

Indonesia. Surat Edaran Direktorat Jendral Bina Marga Nomor: 02/SE/Db/2018: Spesifikasi Umum 2018 Untuk Pekerjaan Konstruksi Jalan dan Jembatan. Jakarta: Direktorat Jendral Bina Marga, 2018.

Kok, Baha Vural, Mehmet Yilmaz and Yunus Erkus. "Effect of Graphite on Mechanical Properties of Stone Mastic Asphalt Pavement". Journal Of Civil Engineering and Management. (2017): 1013-1020. ResearchGate. Web. 5 Februari. 2020. 
Liu, Xiaoming and Shaopeng Wu. "Study On The Graphite and Carbon Fiber Modified Asphalt Concrete". Construction and Building Materials. (2010): 1807-1811. ScienceDirect. Web. 5 Februari. 2020.

Liu, Xiaoming, et al. "Properties Evaluation of Asphalt- Based Composites with Graphite and Mine Powder". Construction and Building Materials. (2007): 121-126. ScienceDirect. Web. 5 Februari. 2020.

Wu, Shaopeng, et al. "Self-Monitoring Electrically Conductive Asphalt-Based Composite Containing Carbon Fillers". Transactions of Nonferrous Metals Society of China. (2006): 512-516. ScienceDirect. Web. 5 Februari. 2020. 